\title{
Development of an Ionic Liquid Based Method for the Preparation of Albumin Nanoparticles
}

\author{
Begüm Demirkurt and Yasar Akdogan*[a]
}

\begin{abstract}
Albumin based nanocarriers have been widely used in drug delivery studies. Here, we developed a water-in-ionic liquid (IL) emulsion-like method to prepare bovine serum albumin (BSA) nanoparticles as alternative to the traditional organic solvents containing techniques. Conformational changes of albumin induced by the imidazolium based ILs at the water-IL interface triggers the BSA nanoparticle formation. The albumin nanoparticle formation are dependent on the experimental parameters and the hydophobicity of the IL. At pH 9.0, using 1.3\%wt of
\end{abstract}

\section{Introduction}

Nanoparticles have been used as drug carriers for a long time. Among all possible different nanocarriers, albumin based nanoparticles have been extensively studied due to their unique properties such as biodegradability, lack of toxicity and antigenicity, and easy preparation. ${ }^{[1]}$ Also, high drug binding capacity of albumin for both hydrophilic and hydrophobic drugs has inspired scientists to prepare drug nanocarriers from albumin protein. ${ }^{[2,3]}$ In addition, the albumin nanoparticle is an attractive candidate for the site-specific delivery of drugs in the body. The possibility of ligand binding on the surface of albumin nanoparticles leads to a specific accumulation in the targeted cells, e.g. tumor cells. ${ }^{[4,5]}$ Also, binding of albumin to albumin binding proteins, $60 \mathrm{kDa}$ glycoprotein (gp60) and secreted protein, acidic and rich in cysteine, (SPARC) enhances uptake of albumin nanoparticles by tumors. ${ }^{[6,7]}$

Formation of albumin nanoparticles is triggered by both decreasing protein intramolecular interactions and increasing protein unfolding. Changing the conditions of medium such as ionic strength, $\mathrm{pH}$, temperature and type of solvent leads to albumin conformational changes, and thus they may result in nanoparticle formation. There are two main methods to prepare albumin nanoparticles; desolvation and emulsification methods. In the desolvation process, addition of organic solvents such as ethanol, methanol or acetone reduces the solubility of the protein in water and leads to nanoparticle formation under constant stirring ${ }^{[8,9]}$ In the presence of cross-

[a] B. Demirkurt, Dr. Y. Akdogan

Materials Science and Engineering Department

İzmir Institute of Technology

35430 Urla, İzmir, Turkey

E-mail: yasarakdogan@iyte.edu.tr

Supporting information for this article is available on the WWW under https://doi.org/10.1002/slct.201801648
BSA in water/1-butyl-3-methyl imidazolium tetrafluoroborate $\left(\mathrm{BmimBF}_{4}\right)(50 / 50 \mathrm{~mol} \%)$ and TX-100/butanol surfactant mixture yields uniformly distributed $200 \mathrm{~nm}$ average sized BSA nanoparticles. Different than $\mathrm{BmimBF}_{4}$, using a more hydrophilic IL, $\mathrm{EmimBF}_{4}$ yielded albumin aggregates. Instead, using a more hydrophobic IL, $\mathrm{HmimBF}_{4}$ produced albumin nanoparticles but a non-uniform size distribution was obtained. These results indicate that the ionic liquids called green and designer solvents can be also used to synthesize albumin nanoparticles. linker such as glutaraldehyde, stable albumin nanoparticles were obtained in the size range of $150-280 \mathrm{~nm} \cdot{ }^{[8]}$ Yet, the used volatile, flammable and toxic organic solvents are harmful for the environment. Also, the waste of them causes storage problems.

In the emulsification method, the aqueous solution of albumin is emulsified in oil phase (castor oil, cyclohexane, dichloromethane, etc.) by using a high-speed homogenizer, high-pressure homogenizer or ultrasonic shear. ${ }^{[10-12]}$ Thermal heating or a cross-linker can be used for the stabilization of the albumin nanoparticles with the help of surfactants. ${ }^{[10,11]}$ For example, BSA nanoparticles $(600 \mathrm{~nm})$ were synthesized by using emulsion-heat stabilization technique. The mixture of basic BSA aqueous solution and castor oil/SPAN-80 was emulsified by a high-speed homogenizer. ${ }^{[10]}$ In the other study, BSA aqueous solution was added into cyclohexane/SPAN-80 mixture and then homogenizer was applied to obtain BSA nanoparticles $(400 \mathrm{~nm}) .^{[11]}$ Also, human serum albumin (HSA) nanoparticles $(130 \mathrm{~nm})$ obtained by emulsification-solvent evaporation process have been used clinically for the delivery of paclitaxel, Abraxane approved by the U.S. Food and Drug Administration (FDA) in 2005, against breast cancer. ${ }^{[13]}$

Although, traditional organic solvents have been commonly used in desolvation and emulsification methods, alternatively, in this study we used ionic liquids (ILs) to synthesize bovine serum albumin (BSA) nanoparticle. lonic liquids are melted salts with melting points below $100^{\circ} \mathrm{C}$, often below room temperature. Their unique properties have made them alternative solvents to traditional organic solvents in different fields such as organic synthesis, catalysis, electrochemistry, purification, pharmacology, etc. ${ }^{[14,15]}$ Since they are non-volatile, non-flammable and recyclable, they are called green solvents. ${ }^{[16]}$ Therefore, synthesizing albumin nanoparticles in an IL based system instead of using organic solvents provides a more environmental friendly synthesizing technique. In addition, physical properties of ILs such as polarity, miscibility, density and 
viscosity can be tuned by selection different anions and cations. Therefore, ILs are also referred to as designer solvents. ${ }^{[17]}$

Serum albumin is a transporter protein for soluble and insoluble compounds in blood. Several drugs binds to BSA at two primary binding sites (site I and site II). ${ }^{[18-21]}$ Its globular structure with three main domains consists of at least $67 \%$ alpha helical structure (Figure $1(\mathrm{~A}))^{\left[{ }^{[22]}\right.}$ The segments of serum
(A)

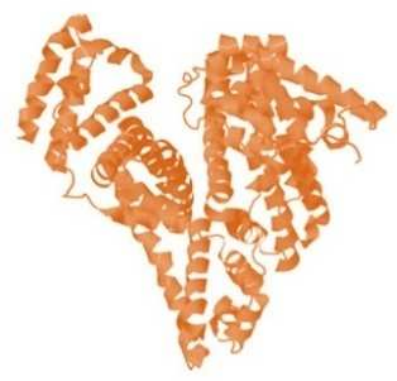

(B)
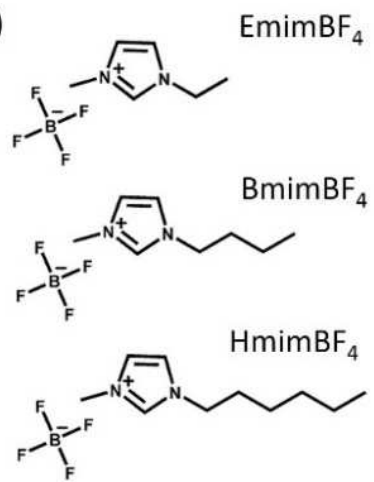

Figure 1. (A) Crystal structure of bovine serum albumin (BSA) (pdb-ID: $3 v 03){ }^{[22]}$ (B) Chemical structures of imidazolium based ionic liquids (ILs): $\mathrm{EmimBF}_{4}, \mathrm{BmimBF}_{4}$ and $\mathrm{HmimBF}_{4}$.

albumin are connected to each other through hydrogen bonds and electrostatic or hydrophobic interactions. They may lose their connections if the interaction to the ILs is favored. Interactions between ILs and albumin are affected by the kinds of anions and cations in ILs. For example, imidazolium based ionic liquids have denaturation effects on the albumin, but choline based ionic liquid such as choline dihydrogen phosphate (dhp) has a stabilizing effect on the albumin structure. ${ }^{[23,24]}$ The denaturing effect of the ILs could be used to initiate albumin nanoparticle formation. Therefore, the chosen anions and cations regulate the albumin nanoparticle formation and affect the physical properties of albumin nanoparticles such as size, size distribution, morphology and stability. Also, for drug transportation, especially for the poor water-soluble drugs, ILs could be very effective to obtain drug loaded albumin nanoparticles in the future. Different types of drugs are soluble in ILs depending on the anions and cations. ${ }^{[17]}$ This could help in encapsulating drugs in the albumin nanoparticle during the nanoparticle preparation. For these reasons, we aim to prepare albumin nanoparticles in an IL based system.

In the literature, ionic liquids have been used in emulsion/ microemulsion systems for the replacements of aqueous phase, oil phase or surfactant molecules. ${ }^{[25]}$ For example, starch nanoparticles were prepared separately in IL/oil, water/IL and water/ oil (IL is surfactant) microemulsion systems. ${ }^{[26-28]}$ Differently, in this work, we developed an emulsion-like technique by using imidazolium based ionic liquids to obtain albumin nanoparticles. We chose three 1-alkyl-3-methylimidazolium tetrafluoroborate, $\mathrm{C}_{n} \mathrm{mimBF}_{4}$, ionic liquids with different alkyl chain lengths, $n=2,4$, and 6: 1-ethyl-3-methylimidazolium tetrafluoroborate $\left(\mathrm{EmimBF}_{4}\right)$, 1-butyl-3-methylimidazolium tetrafluorobo- rate $\left(\mathrm{BmimBF}_{4}\right)$ and 1-hexyl-3-methylimidazolium tetrafluoroborate $\left(\mathrm{HmimBF}_{4}\right)$, respectively (Figure 1 (B)). Increasing the length of alkyl chain of imidazolium cation increases the hydrophobicity of the IL. ${ }^{[29,30]}$ This leads to a polar/nonpolar nanophase separation in the structure of IL. Therefore, addition of water into ILs that have biphasic structures results in the water aggregation. ${ }^{[30-34]}$ Here, we showed that mixtures of ILs and albumin aqueous solution in the presence of surfactants and glutaraldehyde yield albumin nanoparticles after applying a high-speed homogenizer in the formed water pools (Figure 2). Parameters such as $\mathrm{pH}, \mathrm{BSA}$ concentration, water

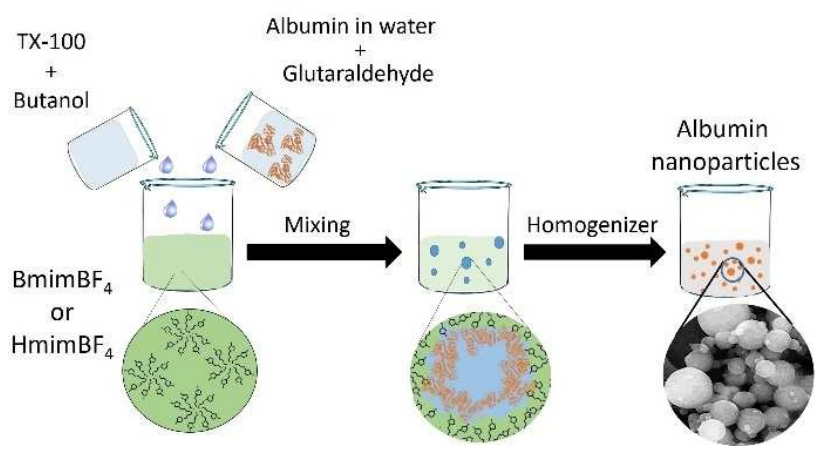

Figure 2. Schematic representation of BSA nanoparticle synthesis using water-in-IL emulsion-like technique.

volume, glutaraldehyde, surfactant and co-surfactant, and the effect of alkyl side chain lengths which strongly influence the BSA nanoparticle formation were studied in detail.

\section{Results and Discussion}

In $\mathrm{C}_{\mathrm{n}} \mathrm{mimBF}_{4}$ ionic liquids with $\mathrm{n}>4$, aggregation of the hydrophobic alkyl side chains of imidazolium ring leads to a nanophase separation from ionic domains consisting of the imidazolium ring and the anion. ${ }^{[30]}$ Therefore, a micelle-like structure is observed. For the water-IL binary system, polar water molecules can interact with ionic domains of $\mathrm{C}_{n} \mathrm{mimBF}_{4}$. For example, by addition of water into the $\mathrm{BmimBF}_{4}$, water molecules are first dissolved and then form water aggregates around the ionic domains of $\mathrm{BmimBF}_{4}$ especially for the intermediate water contents $(50 \mathrm{~mol} \%) .{ }^{[32-34]}$ Although, these water rich domains can be investigated by ${ }^{1} \mathrm{H}$ NMR spectroscopy ${ }_{1}^{[34]}$ their sizes could not be detected by DLS in here due to their dynamic and swinging structures. Since the mixture of $\mathrm{C}_{\mathrm{n}}$ mimBF$_{4}, \mathrm{n}>4$, and water form unstable mesostructures composed of water-rich and IL-rich domains, we developed an emulsion-like method to synthesize albumin nanoparticles in the water-in-ionic liquid (w/IL) system. For albumin nanoparticle preparation, various experimental parameters and the effect of alkyl side chains of ILs were studied in detail. 


\section{Effect of $\mathrm{pH}$ value on the albumin nanoparticle formation}

The influence of aqueous phase $\mathrm{pH}$ value on the nanoparticle formation was studied with three different $\mathrm{pH}$ values including $\mathrm{pH}$ 4.0, 7.0 and 9.0. First, $12 \mathrm{mg}$ of BSA aqueous solution (with glutaraldehyde) in $285 \mu \mathrm{L}$ water was prepared at $\mathrm{pH} 4.0$ and then mixed with $\mathrm{BmimBF}_{4}$ solution in the presence of surfactant (TX-100) and co-surfactant (1-butanol). After that, high speed homogenizer was applied to obtain BSA nanoparticles. But, at pH 4.0, BSA aggregation was observed. SEM image of this aggregation was shown in Figure S1 (A). Next, BSA aqueous solution was prepared at $\mathrm{pH} 7.0$ and then mixed with $\mathrm{BmimBF}_{4}$. After following the same procedure, a limited number of BSA nanoparticles in a film-like BSA structure was detected in the SEM images (Figure S1 (B) and (C)).

On the other hand, further increasing the $\mathrm{pH}$ value of $\mathrm{BSA}$ solution to 9.0, and then mixing with $\mathrm{BmimBF}_{4}$ yielded $\mathrm{BSA}$ nanoparticles with regular spherical shapes (Figure 3 (A) and
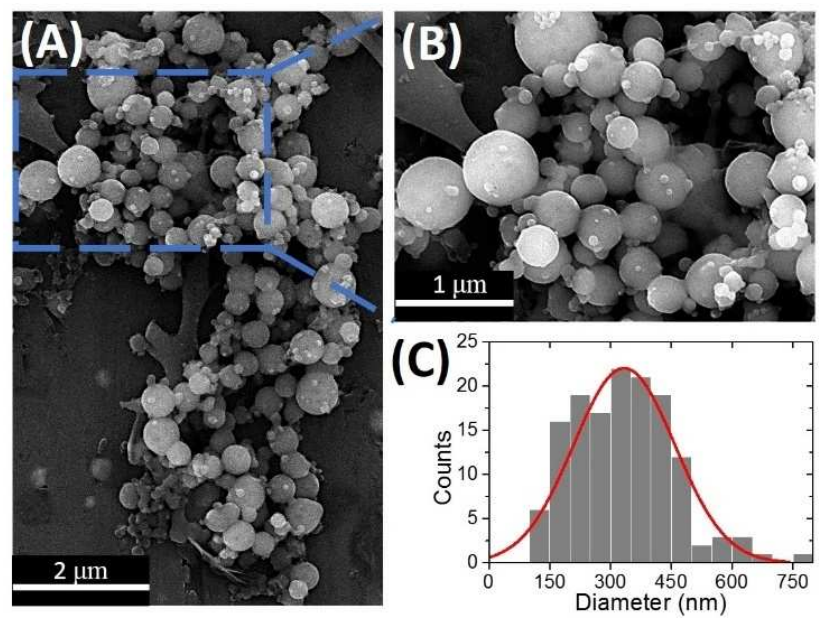

Figure 3. (A, B) SEM images of BSA nanoparticles prepared by addition of $12 \mathrm{mg}$ BSA aqueous solution $(285 \mu \mathrm{L})$ at $\mathrm{pH} 9.0$ to the $\mathrm{BmimBF}_{4}(3 \mathrm{~g})$ based system. (C) Particle size distribution obtained from the SEM image (A). Final BSA concentration is $0.06 \mathrm{mM}$. Mol\% of water and $\mathrm{BmimBF}_{4}$ are $53 \%$ and $44 \%$, respectively.

(B)). Figure 3 (C) shows the particle size distribution obtained from the SEM image in Figure 3 (A). The average size of albumin nanoparticles is $330 \mathrm{~nm}$ with a size distribution between 150 and $600 \mathrm{~nm}$. In addition, DLS provides their average size as around $520 \mathrm{~nm}$ in solution with a PDI 0.271 (Figure S2 (A)). Also, the zeta potential of the BSA nanoparticles was found as $-11 \mathrm{mV}$. Obtaining higher average particle size in solution by DLS is reasonable due to the formation of hydration shell and/or swelling nanoparticles with water.

These observations are in good agreement with the earlier works in which smaller albumin nanoparticles were obtained at $\mathrm{pH} 8.0$ - 9.0 with the desolvation technique. ${ }^{[8,35]}$ The influence of $\mathrm{pH}$ on the isolated albumin nanoparticle formation can be explained by the charge effects. Although, the structure of albumin remains stable between $\mathrm{pH}$ values of 4.0 and 9.0, the charge of albumin changes from positive to negative with reported isoelectric points in the range from 4.8 to $5.6 .^{[36]}$ At $\mathrm{pHs} 4.0,7.0$ and 9.0, the reported charges of BSA are $+10,-13$, and -26 , respectively. ${ }^{[36]}$ The absolute value of charge of BSA at $\mathrm{pH} 9.0$ is about twice the absolute value of charges of BSA at $\mathrm{pH} 4.0$ and 7.0. Therefore, higher electrostatic repulsive forces at $\mathrm{pH} 9.0$ keep the formed albumin nanoparticles away from each other which avoids the agglomeration. In addition, the albumin nanoparticle formation can be affected by the types of intermolecular interactions between $\mathrm{BmimBF}_{4}$ and $\mathrm{BSA}$ which are also $\mathrm{pH}$ dependent. In addition to hydrogen bonding and hydrophobic interactions which exist between $[\mathrm{Bmim}]^{+}$and $\mathrm{BSA}$, a higher electrostatic attraction between $[\mathrm{Bmim}]^{+}$and BSA takes place at $\mathrm{pH} 9.0$ due to a net higher negative charge on albumin. At pH 9.0, the combination of these forces possibly supports the albumin nanoparticle formation and stabilization.

\section{Effect of BSA concentration on the albumin nanoparticle formation}

Effect of BSA concentration (in $285 \mu \mathrm{L}$ water, at $\mathrm{pH} 9.0$ ) on the size of BSA nanoparticles was studied with $0.5,4$ and $12 \mathrm{mg}$ of BSA. Addition of $12 \mathrm{mg}$ BSA $(0.6 \mathrm{mM}, 4 \mathrm{wt} \%$ in water) containing water into $\mathrm{BmimBF}_{4}$ yielded $\mathrm{BSA}$ nanoparticles (average $330 \mathrm{~nm}$ ) with a size distribution between 150 and $600 \mathrm{~nm}$ (Figure 3). In order to obtain smaller nanoparticles with a narrower size distribution, we decreased the BSA content from $12 \mathrm{mg}$ to $4 \mathrm{mg}(0.2 \mathrm{mM}, 1.3 \mathrm{wt} \%$ in water). As a result, BSA nanoparticles of $200 \mathrm{~nm}$ average size with a size distribution between 100 and $300 \mathrm{~nm}$ was obtained (Figure 4). In

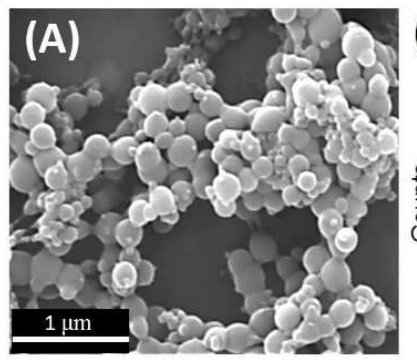

(B)

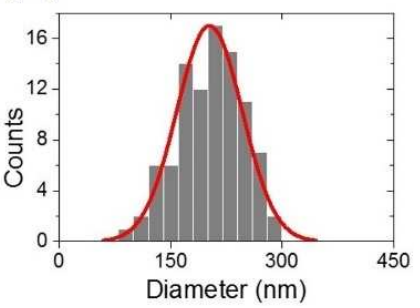

Figure 4. (A) SEM image of BSA nanoparticles prepared by addition of $4 \mathrm{mg}$ of $\mathrm{BSA}$ aqueous solution $(285 \mu \mathrm{L})$ at $\mathrm{pH} 9.0$ to the $\mathrm{BmimBF}_{4}(3 \mathrm{~g})$ based system. (B) Particle size distribution obtained from the SEM image (A). Final $\mathrm{BSA}$ concentration is $0.02 \mathrm{mM}$. Mol\% of water and $\mathrm{BmimBF}_{4}$ are $53 \%$ and $44 \%$, respectively.

addition, DLS provided their average size as around $450 \mathrm{~nm}$ in solution with a PDI 0.175 (Figure S2 (B). The sizes obtained from DLS are larger compare to the results obtained from SEM image, just like the results of sample obtained with $12 \mathrm{mg}$ of BSA.

Lomis et al. showed that decreasing the BSA concentration in chloroform/water solution yields smaller BSA nanoparticles in the emulsion-solvent evaporation method. ${ }^{[2]}$ Decreasing the BSA concentration leads to a decrease in the BSA-BSA 
interactions. This avoids the formation of larger particles or agglomeration of BSA clusters. Also, BSA concentration directly affects the microviscosity of the system. Increasing the microviscosity in the nanodroplets with higher BSA concentration may cause additional resistance against applied shear stress during high-speed homogenization. This may hinder smaller nanodroplet formation. On the other hand, further decreasing the BSA content to $0.5 \mathrm{mg}(0.025 \mathrm{mM}, 0.16 \mathrm{wt} \%)$ in water did not yield albumin nanoparticles (Figure S3). A film-like formation was detected. This could be originated from the insufficient numbers of BSA to interact with and support to each other.

\section{Effect of water volume on the albumin nanoparticle formation}

$\mathrm{BmimBF}_{4}$ is a hydrophilic ionic liquid, and it is macroscopically miscible with water at any concentrations. However, their mixtures are not homogeneous on the microscopic scale especially for the intermediate water contents $(50 \mathrm{~mol} \%)^{[34]}$ Above the critical aggregation concentration $(C A C=0.45 \mathrm{M})$ of $\mathrm{BmimBF}_{4}$, unstable mesostructures composed of water-rich and IL-rich domains were obtained. ${ }^{[31-33]}$ Therefore, increasing the water content in $\mathrm{BmimBF}_{4}$ phase produces water aggregates/ pools. In Figure 3, we showed that $285 \mu \mathrm{L}$ of water $(53 \% \mathrm{~mol})$ was used to solve BSA and then mixed with $3 \mathrm{~g}$ of $\mathrm{BmimBF}_{4}$ (4.5 $\mathrm{M}, 44 \% \mathrm{~mol}$ ) to obtain BSA nanoparticles.

However, dissolving the same amount of BSA (12 mg) in less or more water phase gave different results. Figure 5 (A)
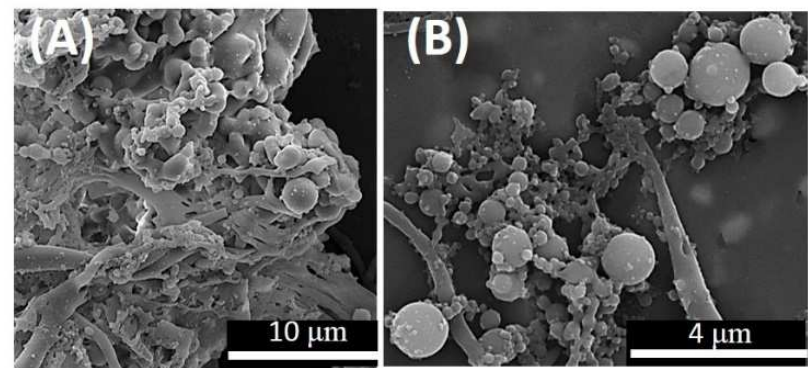

Figure 5. SEM images of BSA samples prepared by addition of $165 \mu \mathrm{L}(\mathrm{A})$ and $525 \mu \mathrm{L}(\mathrm{B})$ of $\mathrm{BSA}\left(12 \mathrm{mg}\right.$ ) aqueous solutions to the $\mathrm{BmimBF}_{4}$ based systems.

and (B) show the SEM images of BSA samples obtained upon addition of $165 \mu \mathrm{L}(40 \% \mathrm{~mol})$ and $525 \mu \mathrm{L}(67 \% \mathrm{~mol})$ of BSA containing water solutions into $3 \mathrm{~g}$ of $\mathrm{BmimBF}_{4}$, respectively. In Figure 5 (A), mostly insoluble albumin aggregates were observed when $165 \mu \mathrm{L}$ water $(40 \% \mathrm{~mol})$ was used. By decreasing the water content from $285 \mu \mathrm{L}$ ( $53 \% \mathrm{~mol})$ to $165 \mu \mathrm{L}$ $(40 \% \mathrm{~mol}), \mathrm{BSA}$ concentration increases from $0.6 \mathrm{mM}$ to $1.1 \mathrm{mM}$ since $12 \mathrm{mg}$ of BSA used for both conditions. It seems that during the albumin nanoparticle formation, close interactions between BSA proteins turned into larger aggregates with the help of glutaraldehyde cross linking process. On the other hand, by keeping the BSA amount constant, increasing the volume of water phase from $285 \mu \mathrm{L}(53 \% \mathrm{~mol})$ to $525 \mu \mathrm{L}(67 \%$ mol) produced larger BSA nanoparticles with non-uniform size distributions (Figure 5 (B)). This can be explained by the formation of larger water aggregates with increasing the water content. Also, applying the homogenizer with the same speed and time to a higher volume of water contained system might not be energetically successful to lead small nanoparticles with uniform size distributions.

\section{Effects of using glutaraldehyde and surfactants on the albumin nanoparticle formation}

As a cross-linker glutaraldehyde has been used mostly to stabilize the formed albumin nanoparticles. ${ }^{[8]}$ It can cross-link proteins through amino acids with free amine sites such as lysine. Here, glutaraldehyde is required to stabilize the prepared albumin nanoparticles too. Without glutaraldehyde, albumin proteins form aggregates upon mixing with $\mathrm{BmimBF}_{4}$ in the emulsion-like system (Figure S4). This shows the importance of using glutaraldehyde as cross-linker in this system to obtain stable albumin nanoparticles.

Furthermore, effects of surfactant (TX-100) and co-surfactant (1-butanol) on the albumin nanoparticle synthesis were studied. Surfactant molecules can decrease the interfacial tension between immiscible liquids in a system. This increases miscibility, colloidal stability and dispersion of nanoparticles in liquid. ${ }^{[34]}$ In our system, BSA nanoparticle formation was not achieved without TX-100 and 1-butanol. As already shown in Figure 3 and 4, using $50 \mathrm{mM}$ of non-ionic surfactant TX-100 (with $140 \mathrm{mM}$ of 1-butanol) below its critical micelle concentration $(\mathrm{CMC})^{[37]}$ in $\mathrm{BmimBF}_{4}$ helped to obtain BSA nanoparticles. Besides, using higher amount of surfactants such as $125 \mathrm{mM}$ of TX-100 (with $420 \mathrm{mM}$ of 1-butanol) caused BSA aggregation (Figure $S 5(A)$ ). Behera et al. showed that the CMC value of TX-100 increases with $\mathrm{BmimBF}_{4}$ concentration in the aqueous solution. ${ }^{[37]}$ At $30 \mathrm{wt} \%$ of $\mathrm{BmimBF}_{4}$ solution, TX-100 does not form aggregation up to $50 \mathrm{mM}$ of TX-100. ${ }^{[37]}$ Therefore, in here, it is not expected to observe TX-100 (50 mM) aggregation in the $85 \mathrm{wt} \%$ of $\mathrm{BmimBF}_{4}$ aqueous solution. But, $125 \mathrm{mM}$ of TX-100 may form aggregation in our system and may cause the coalescence of BSA nanoparticles. This shows that the ratio of surfactants in the system plays a significant role for the BSA nanoparticle formation. In addition, Figure S5 (B) shows the role of the co-surfactant 1-butanol in this system. 1-butanol molecules may have aligned on the interface of the water/IL along with the TX-100 molecules and thus they enhanced water solubility of the obtained nanoparticles. Therefore, BSA aggregation was observed without using 1-butanol in the system (Figure S5 (B)).

\section{Effects of alkyl chain lengths of ILs on the albumin nanoparticle formation}

Structures of ILs-water mixtures are strongly dependent on the choice of the anion and cation. $\mathrm{BF}_{4}{ }^{-}$ion containing imidazolium based ILs show hydrophilic properties, and their hydrophilicity decreases with increasing the alkyl chain lengths of 
the imidazolium ring. ${ }^{[38]}$ Therefore, in IL-water mixture, water pool formation increases with longer alkyl chain of IL. In addition, imidazolium types of ILs have denaturation effect on the albumin structure. Increasing the alkyl side chain of imidazolium cations leads to a higher albumin unfolding due to the enhanced hydrophobic interactions. ${ }^{[23]}$ Here, we studied three imidazolium based ionic liquids $\left(\mathrm{EmimBF}_{4}, \mathrm{BmimBF}_{4}\right.$ and $\mathrm{HmimBF}_{4}$ ) with different alkyl chain lengths to obtain albumin nanoparticles. Addition of $4 \mathrm{mg}$ BSA solution ( $285 \mu \mathrm{L}$ water) into $3 \mathrm{~g}$ of $\mathrm{EmimBF}_{4}$ in the presences of glutaraldehyde and surfactants did not produce BSA nanoparticles after applying the high-speed homogenizer. Figure 6 (A) shows the SEM

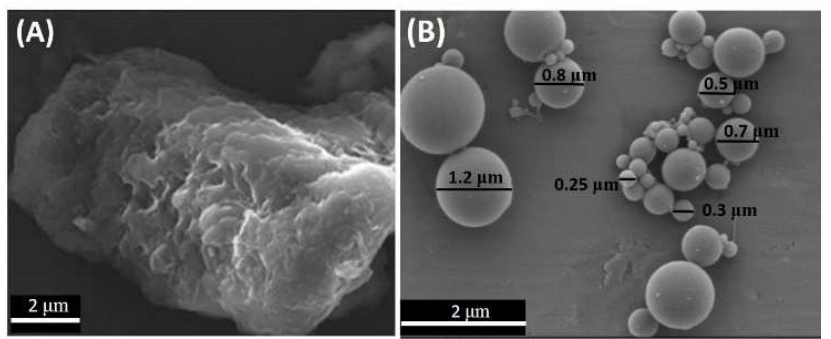

Figure 6. (A) SEM image of BSA aggregates obtained by using $\mathrm{EmimBF}_{4}$ and (B) SEM image of BSA nanoparticles obtained by using $\mathrm{HmimBF}_{4} .4 \mathrm{mg}$ of BSA aqueous solution $(285 \mu \mathrm{L})$ at $\mathrm{pH} 9.0$ was added to the ILs $(3 \mathrm{~g})$ based system. Final BSA concentration is $0.015 \mathrm{mM}$. Mol\% of water and ILs are $53 \%$ and $44 \%$, respectively.

image of $\mathrm{BSA}$ aggregates obtained by using $\mathrm{EmimBF}_{4}$. As already shown in Figure 3 and 4, BSA nanoparticles can be obtained in the $\mathrm{BmimBF}_{4}$ based system. Increasing the alkyl side chain of imidazolium cation favors the polar/nonpolar nanophase separation in ILs. Therefore, water molecules can be aggregated in the polar regions of $\mathrm{BmimBF}_{4}$ which stimulate the nanoparticle formation. Since the hydrophobicity of ethyl groups is not strong enough to create robust nonpolar domains in $\mathrm{IL}$, water molecules can be homogeneously distributed in EmimBF4 more than in BmimBF4. Thus, they do not form water pools extensively in $\mathrm{EmimBF}_{4}$ which are necessary for the albumin nanoparticle formation.

Further increasing the length of alkyl side chain of imidazolium cation from butyl to hexyl, water solubility decreases. Thus, this leads to larger water pools formation around the polar regions of $\mathrm{HmimBF}_{4}$. Addition of $4 \mathrm{mg} \mathrm{BSA}$ solution ( $285 \mu \mathrm{L}$ water) into $3 \mathrm{~g}$ of $\mathrm{HmimBF}_{4}$ in the presences of glutaraldehyde and surfactants produce BSA nanoparticles after applying the high-speed homogenizer (Figure 6 (B)). As expected, larger water pools formed in the water-HmimBF system leaded to the larger BSA nanoparticles compared to those formed in the water-BmimBF4 system. Spherical BSA nanoparticles with a broad size distribution between $0.2 \mu \mathrm{m}$ and $1.2 \mu \mathrm{m}$ were obtained in the water- $\mathrm{HmimBF}_{4}$ microemulsion like system.

\section{Conclusions}

Organic solvents have been commonly used to prepare albumin nanoparticles. However, ionic liquids have been considered as green replacements for organic solvents due to their unique properties in addition to their designability features. Therefore, alternatively, here an imidazolium based ionic liquid of $\mathrm{BmimBF}_{4}$ was used to prepare albumin nanoparticles.

It has been known that water in $\mathrm{BmimBF}_{4}$ at intermediate levels (e.g. 50 mol\%) forms water aggregates/pools. ${ }^{[31-34]}$ These water aggregates are strongly dependent on the alkyl chain length of the imidazolium cation. Increasing the alkyl chain length forms larger water pools in the water-IL binary mixtures. Here, addition of BSA aqueous solution with glutaraldehyde into $\mathrm{BmimBF}_{4}$ (with TX-100 and 1-butanol) forms an emulsionlike system upon applying high-speed homogenizer. Interactions between $\mathrm{BmimBF}_{4}$ and $\mathrm{BSA}$ at the water/BmimBF${ }_{4}$ interface denature the BSA. After that, high-speed homogenization converted denatured BSA into BSA nanoparticles with the help of glutaraldehyde (Figure 2). By choosing the right experimental parameters including the $\mathrm{pH}$ value, concentration of BSA, volume of water solution and surfactant/co-surfactant ratios, smaller BSA nanoparticles $(200 \mathrm{~nm}$ ) with uniform size distribution can be obtained. Furthermore, using an IL with a shorter alkyl chain such as EmimBF$_{4}$ did not yield BSA nanoparticles, but using an IL with a longer alkyl chain, $\mathrm{HmimBF}_{4}$, produced larger BSA nanoparticles with a broad size distribution. In more hydrophobic $C_{n}$ mimBF$_{4}$ ionic liquids with $n=4$ and 6 , water pools were created upon addition of water at an intermediate level, which help nanoparticle formation. This shows the importance of water pools formation in the water-IL system for the BSA nanoparticle preparation. Here, we showed that ionic liquids can be good candidates for use in the preparation of albumin nanoparticles. The developed method is, of course, not restricted to bare albumin nanoparticle formation, could be applied to the field of drug loaded nanoparticles in the further studies.

\section{Supporting Information Summary}

Experimental details are given in the supporting information. Table S1 summarized the sample preparation. SEM images and DLS results were given in Figure S1 - S5.

\section{Acknowledgements}

Authors thank IZTECH Center for Materials Research and IZTECH Biotechnology and Bioengineering Research Center. This work was financially supported by IZTECH Scientific Research Projects under grant 2015_iYTE_01

\section{Conflict of Interest}

The authors declare no conflict of interest. 
Keywords: Albumin nanoparticles · drug carrier • emulsion ionic liquids

[1] A. O. Elzoghby, W. M. Samy, N. A. Elgindy, J. Control. Release 2012, 157, 168-182.

[2] N. Lomis, S. Westfall, L. Farahdel, M. Malhotra, D. Shum-Tim, S. Prakash, Nanomaterials 2016, 6, (116), 1-17.

[3] X. Tang, G. Wang, R. Shi, K. Jiang, L. Meng, H. Ren, J. Wu, Y. Hu, Drug Deliv. 2016, 23, 2686-2696.

[4] L. Zhang, S. Hou, S. Mao, D. Wei, X. Song, Y. Lu, Int. J. Pharm. 2014, 287, $155-162$.

[5] J. S. Choi, N. Meghani, Colloids Surf. B Biointerfaces 2016, 145, 653-661.

[6] N. Desai, V. Trieu, Z. Yao, L. Louie, S. Ci, A. Yang, C. Tao, T. De, B. Beals, D. Dykes, P. Noker, R. Yao, E. Labao, M. Hawkins, P. Soon-Shiong, Clin.Cancer Res. 2006, 12, 1317-1324.

[7] K. Komiya, T. Nakamura, C. Nakashima, K. Takahashi, H. Umeguchi, N. Watanabe, A. Sato, Y. Takeda, S. Kimura, N. Sueoka-Aragane, Onco. Targets Ther. 2016, 9, 6663-6668.

[8] K. Langer, S. Balthasar, V. Vogel, N. Dinauer, H. Von Briesen, D. Schubert, Int. J. Pharm. 2003, 257, 169-180.

[9] B. Von Storp, A. Engel, A. Boeker, M. Ploeger, K. Langer, J. Microencapsul. 2012, 29, 138-146.

[10] L. Yang, F. Cui, D. Cun, A. Tao, K. Shi, W. Lin, W. , Int. J. Pharm. 2007, 340, 163-172.

[11] F. Crisante, I. Francolini, M. Bellusci, A. Martinelli, L. D'llario, A. Piozzi, Eur. J. Pharm. Sci. 2009, 36, 555-564.

[12] Q. Zhang, L. Zhang, L. Zemin, X. Xie, X. Gao, X. Xu, AAPS Pharm. Sci. Tech. 2017, 18, 2977-2986.

[13] N. Desai, Nanoparticle Albumin-Bound Paclitaxel (Abraxane ${ }^{\oplus}$ ). In: M. Otagiri, V. Chuang (eds) Albumin in Medicine. 2016, Springer, Singapore.

[14] Z. Qiu, J. Texter, Curr. Opin. Colloid Interface Sci. 2008, 13, 252-262.

[15] K. Ghandi, Green Sustain. Chem. 2014, 4, 44-53.

[16] S. Goindi, R. Kaur, R. Kaur, Int. J. Pharm. 2015, 495, 913-923.

[17] N. Adawiyah, M. Moniruzzaman, S. Hawatulaila, M. Goto, Med. Chem. Comm. 2016, 7, 1881-1897.

[18] J. Ghuman, P. A. Zunszain, I. Petitpas, A. A. Bhattacharya, M. Otagiri, S. Curry, J. Mol. Biol. 2005, 353, 38-52.

[19] F. Yang, C. Bian, L. Zhu, G. Zhao, Z. Huang, M. Huang, J. Struct. Biol. 2007, 157, 348-355.
[20] D. Tatlidil, M. Ucuncu, Y. Akdogan, Phys. Chem. Chem. Phys. 2015, 17, 22678-22685

[21] Y. Akdogan, M. Emrullahoglu, D. Tatlidil, M. Ucuncu, G. Cakan-Akdogan, Phys. Chem. Chem. Phys. 2016, 18, 22531-22539.

[22] K. A. Majorek, P. J. Porebski, A. Dayal, M. D. Zimmerman, K. Jablonska, A. J. Stewart, M. Chruszcz, W. Minor, Mol. Immunol. 2012, 52, 174-182.

[23] Y. Akdogan, M. J. N. Junk, D. Hinderberger, Biomacromolecules 2011, 12, 1072-1079.

[24] Y. Akdogan, D. Hinderberger, J. Phys. Chem. B 2011, 115, 15422-15429.

[25] J. Kuchlyan, N. Kundu, N. Sarkar, Curr. Opin. Colloid Interface Sci. 2016 25, 27-38.

[26] G. Zhou, Z. Luo, X. Fu, J. Agric. Food Chem. 2014, 62, 8214-8220.

[27] G. Zhou, Z. Luo, X. Fu, Ind. Crops Prod. 2014, 52, 105-110.

[28] X. Wang, H. Chen, Z. Luo, X. Fu, Carbohydr. Polym 2016, 138, 192-200.

[29] T. Mendez-Morales, J. Carrete, O. Cabeza, L. J. Gallego, L. M. Varela, J. Phys. Chem. B 2011, 115, 6995-7008.

[30] Y. Akdogan, J. Heller, H. Zimmermann, D. Hinderberger, Phys. Chem. Chem. Phys. 2010, 12, 7874-7882.

[31] B. Wu, L. Zhang, Y.M. Zhang, H. P. Wang, Chem. Eur. J. 2009, doi:10.1002/chem.200901098.

[32] D. R. Kattnig, Y. Akdogan, I. Lieberwirth, D. Hinderberger, Mol. Phys. 2013, 111, 2723-2737.

[33] D. R. Kattnig, Y. Akdogan, C. Bauer, D. Hinderberger, Z. Phys. Chem. 2012, 226, 1363-1378.

[34] K. Saihara, Y. Yoshimura, S. Ohta, A. Shimizu, Sci. Reports 2015, 5, 10619.

[35] S. Sebak, M. Mirzaei, M. Malhotra, A. Kulamarva, S. Prakash, Int. J. Nanomed. 2010, 5, 525-532.

[36] L. R. S. Barbosa, M. G. Ortore, F. Spinozzi, P. Mariani, S. Bernstorff, R. Itri, Biophys. J. 2010, 98, 147-157.

[37] K. Behera, M. D. Pandey, M. Porel, S. Pandey, J. Chem. Phys. 2007, 127, 184501.

[38] H. Heinz, C. Pramanik, O. Heinz, Y. Ding, R. K. Mishra, D. Marchon, R. J. Flatt, I. Estrela-Lopis, J. Llop, S. Moya, R. F. Ziolo, Surf. Sci. Rep. 2017, 72, $1-58$.

[39] S. Feng, G. A. Voth, Fluid Phase Equilib. 2010, 294, 148-156.

Submitted: May 30, 2018

Accepted: September 6, 2018 